\title{
A ARTE DO SOCIODRAMA: REVISÃO BIBLIOGRÁFICA À AÇÃO CULTURAL
}

\author{
THE ART OF SOCIODRAMA: BIBLIOGRAPHICAL REVIEW FOR CULTURAL \\ ACTION
}

Priscila Andreoni Ribeiro ${ }^{1}$

RESUMO: Este trabalho pretende desenvolver princípios básicos para aplicação do sociodrama à educação e às artes visando uma ação cultural. Estes princípios foram divididos em: I) As raízes no teatro do Espontâneo (de Moreno e Aguiar) e do Oprimido (de Boal); 2) O contexto da arte contemporânea onde o espectador passa a ser o ator do espetáculo, numa demonstração de arte popular; 3) A construção do conhecimento pela reflexão e vivência dramática, possibilitando uma transformação cultural. Estes princípios compõem uma proposta de roteiro de ação cultural sendo o sociodrama é um método importante a ser considerado em ações transformadoras, educacionais ou culturais.

Palavras-chaves: Sociodrama. Ação Cultural. Educação. Arteterapia expressiva.

ABSTRACT: This work intends to develop basic principles for the application of sociodrama to education and the arts with a view to cultural action. These principles were divided into: I) The roots of the Spontaneous theater (by Moreno and Aguiar) and the Oppressed (by Boal); 2) The context of contemporary art where the spectator becomes the actor in the show, in a demonstration of popular art; 3) The construction of knowledge through reflection and dramatic experience, enabling a cultural transformation. These principles make up a proposal for a cultural action script, and sociodrama is an important method to be considered in transformative, educational or cultural actions.

Keywords: Sociodrama. Cultural Action. Education. Expressive Art Therapy.

\section{INTRODUÇÃO}

Este trabalho refere-se ao método de sociodrama desenvolvido pela visão das artes, enquanto roteiro e método de Teatro aplicado às culturas e educação, não somente do Teatro ao teatro, mas às diversas práticas educacionais. O problema a ser tratado é sobre um método comum de ação visando o desenvolvimento de conhecimento ou ação

\footnotetext{
I Pós-graduação em Psicopedagogia - FAMART - 2021. E-mail: andreonipriscila@gmail.com.
} 

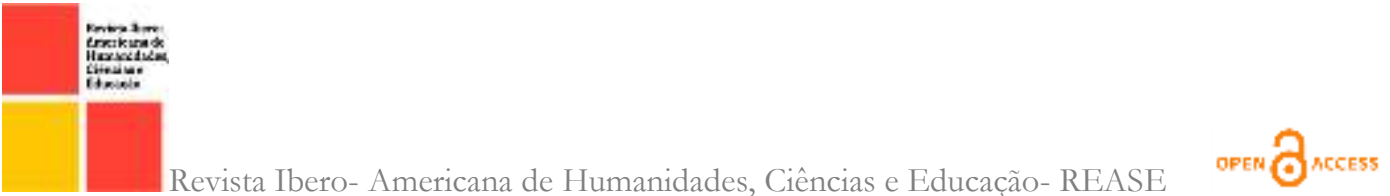

cultural, em grupos de pessoas em qualquer geração e organização. A pergunta que se coloca é qual método utilizar visando o desenvolvimento de uma ação cultural?

O objetivo principal deste artigo é a expansão aplicativa do método de sociodrama de Moreno à Educação e Cultura, pela apuração de conceitos fundamentais a este método a ser aplicado a uma ação cultural. A relevância deste estudo está na elaboração de um roteiro básico para aplicação do sociodrama à ação cultural. Este roteiro serve de guia para o fomento de ações educacionais e culturais na nossa sociedade.

A metodologia é de revisão bibliográfica sobre o tema e aplicação da experiência de participação ativa em Psicodrama Público (CCSP e Diadema). A pesquisa empírica e observacional conta até o momento 6 anos de vivências e experiências em grupos de interesses distintos e diversos. O grupo era formado espontaneamente pelo CCSP e Diadema, somando de 30 a 80 pessoas por encontro uma vez por semana, de 2,5 horas cada.

Uma das formas de iniciar na arte da dramatização e no conceito de ação é pensar nas palavras representativas de "ação", que são os verbos. Os verbos sempre indicam um movimento e a finalidade utilizada é indefinida e ampla. Trabalhar a dramatização pela vinculação a um verbo representativo da cena que se quer construir é o início e o fundamental. A consciência sobre as mais diversas transformações das diferentes culturas, o desenvolvimento de uma base questionadora é o fundamento para uma ação cultural.

\section{DESENVOLVIMENTO}

A arte do drama está fundamentada no princípio básico do como contar uma história. É senso comum que toda história deve conter início, meio e fim. O início é uma introdução (exposição do tema e finalidade), o meio é o recheio (o desenvolvimento do tema visando atingir a finalidade) e o fim é a conclusão (a sedimentação resumida do conhecimento adquirido).

O "expressar" passa por elaborar e trabalhar para nomear em várias linguagens diferentes, o eu subjetivo visando alcançar o outro-espectador, o público. Qual a 
motivação para expressar este subjetivo ao público? A motivação ou razão para satisfação do desejo de expressão ao outro está voltada à valorização do dividir e compartilhar uma experiência, história ou acontecimento. Compartilhar se restringe à ação de expressar ao outro uma história. Se haverá troca, aceitação ou rejeição a esta história é outro caminho e intenção.

\section{INÍCIO - O TEATRO DO ESPONTÂNEO E DO OPRIMIDO}

O teatro do espontâneo introduziu uma nova arte, a arte do momento, a qual de início nada tinha a ver com terapia. O primeiro momento foi em I9II, com o teatro para crianças, em Viena; e depois com um teatro para adultos, entre 1922 e 1925. O teatro do espontâneo, segundo Moreno (2012, p.20-22), significa a forma de comunicação com o público, menos rígida e mais realista. Para Moreno, o local do si mesmo é a espontaneidade. "Quando a espontaneidade cresce o si mesmo se expande. Pelo estímulo à espontaneidade o indivíduo exprime o si mesmo sem rótulos ou interpretações alheias."

No teatro convencional, o momento da "performance" está dissociado do momento da criação. Os atores são receptáculos de uma criatividade originada no passado, onde o texto e a interpretação guardam o momento da criatividade. Porém o momento da exibição ao público é um momento de apresentação mecânica desta criatividade. Seria a expressão da criatividade já morta. Assim, o teatro do espontâneo é o veículo organizado para a apresentação do drama do momento. O ato criativo é definido com três características, a espontaneidade, o inesperado e o irreal. "O estado inicial de um trabalho artístico quase nunca é um estado perfeito. Uma das funções do teatro do espontâneo é acolher as obras de arte abortadas".

Para Moreno (2012, p.57), o improviso é diferente da dramatização espontânea, já que o improviso tem o significado de uma margem de manobra por parte do ator em determinadas situações. A dramatização do espontâneo é a arte do momento, devendo evitar os diálogos e textos rígidos e dogmáticos. No espontâneo, há espaço para abordar o desejo como a motivação própria que movimenta as pessoas, como força original que impulsiona em determinada direção ou caminho. 


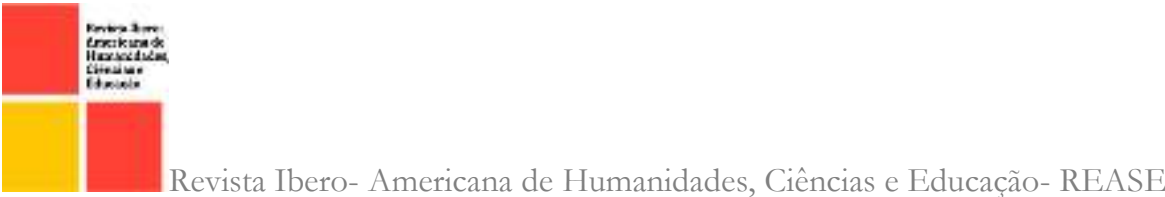

Nesta linha, para além de Moreno, surge o princípio da motivação pelo desejo subjetivo ou coletivo. O espontâneo, entendido como motivação para ação, torna-se raiz principal do desenvolvimento da arte da dramatização.

Moyses Aguiar (2011, p.7), fundador da Companhia de Teatro Espontâneo (1980), segue a linha do teatro-debate, ressalta que o teatro do espontâneo, antes de qualquer conexão com a psicoterapia, é uma forma de arte, já que a arte em si é transformadora. O teatro do Espontâneo fala mais de arte do que de psicologia.

É necessário buscar e valorizar os caminhos já percorridos pelo teatro no Brasil de forma a adequar os princípios do método de sociodrama a um teatro com raízes brasileiras e atuais. Há duas linhas de trabalhos do cenário brasileiro através das artes dramáticas, importantes e ao encontro do significado de teatro espontâneo apontado por Moreno, quais sejam, o Teatro do Oprimido pelo teatro de Arena de São Paulo e o Teatro Oficina. Ambos em linhas construtivistas e valorizando o desenvolvimento do pensamento crítico e atual. Com muitas contribuições à cultura nacional pela proposta de trabalho da cena brasileira.

O teatro do Oprimido em Boal (2014, p. 135), determina que:

[...] no princípio o teatro era o povo livre cantando ao ar livre. O Carnaval e a festa. Depois, a classe dominante se apropriou do teatro e construiu muros divisórios. Dividiram o povo, separando atores de espectadores: gente que faz e gente que observa...O povo oprimido se liberta e outra vez conquista o teatro. É necessário derrubar muros!

Com a poética do oprimido, Boal propõe a própria ação, "onde o espectador assume um papel de protagonista, transforma a ação dramática inicialmente proposta e ensaia soluções possíveis, debate projetos modificadores." (p. 138). Tenta mostrar um caminho pelo qual o povo reassume seu papel de protagonista no teatro e na sociedade. "O espectador liberado se lança a uma ação. Não importa que seja fictícia, mas é uma ação."(p. 139)

Para a poética do oprimido, a sociedade de classes não somente explora a mão de obra no trabalho, mas também culturalmente define um papel de passividade ao povo diante da vida, que é representada pelo teatro. Esta passividade é assumida pela alienação do povo e pessoas de sua capacidade de agir nas situações de sua vida e o teatro é um instrumento de ação cultural onde o povo pode se libertar e reassumir o 
protagonismo de ação na sociedade. Boal menciona o teatro de Arena de São Paulo, que lutou contra a crise dos anos 8o-9o e iniciou um processo de empoderamento do povo pelo teatro pelas escolhas de temas de conscientização da alienação do povo, provocando uma catarse, chamando à ação.

O teatro Oficina é mais um exemplo desta tentativa de inserção social do teatro. Segundo Lima (1983, p 163-171),

O Oficina soube abrir-se e incorporar, paulatinamente, as mais significativas transformações da cena ocidental, sempre em posição de vanguarda, vindo a alcançar um destaque absoluto com sua encenação de O Rei da Vela, em 1967, obra que catalisa o movimento tropicalista.

As modalidades de teatro aqui apresentadas levam à reflexão do que seja Teatro. Há várias técnicas de apresentação e comunicação com o público, mas o fundamental para o iniciante em teatro é focar na arte dramática, na técnica de construir ou destruir drama (ação) atrelado ao seu contexto cultural, a cena social.

\section{MEIO - O PÚBLICO COMO PROTAGONISTA E ATOR}

O público como ator é um manifesto pelo direito de todos à expressão de sua subjetividade ao outro. Este direito quando exercido pode ser terapêutico ao sujeito e ao público. O teatro do espontâneo é aquele que se fundamenta na empatia de mão dupla, em contraposição ao fenômeno da transferência. Terapêutico no sentido de tratamento, digestão da história contada, do contexto proposto.

Desgranges (2003, p.27-79), apresenta o conceito de pedagogia do espectador:

[...] necessária presença de um outro que exija diálogo, pela fundamental participação criativa desse jogador no evento teatral, participação que se efetiva na sua resposta às proposições cênicas, em sua capacidade de elaborar os signos trazidos à cena e 'formular um juízo próprio dos sentidos...O exercício dramático sensibiliza para uma recepção mais atenta, crítica, e aberta a concepções cênicas novas e divergentes, ao mesmo tempo que a ida ao teatro, o diálogo com as obras contemporâneas, possibilita melhor aproveitamento dessas atividades em sala de aula."..."Nos jogos de improvisação dramática, o participante pode exercer todas, ou quase todas, as funções artísticas da criação teatral, podendo desempenhar, na criação de suas pr6prias cenas, ao mesmo tempo, a função de dramaturgo, ator, diretor, cenógrafo, etc. A exploração das infindáveis possibilidades de construção de uma cena favorece o aprendizado da linguagem, assim como a acuidade da observação acerca das particularidades de cada encenação, chamando a atenção do aluno-espectador para as opções estéticas dos diversos artistas da criação teatral. 
Já outras linhas foram desenvolvidas buscando ativar o público nas artes. Bertold Brecht desenvolveu o conceito da peça-didática, em que se oferece ao público uma cena rápida, induzindo-o a experimentar diferentes formas de dramatização estimulando a busca de alternativas cênicas estimulando potencializar a expressão do sentido atribuído ao texto.

Em Boal (2014, p.I43-I44), o povo-espectador pode ser convertido em ator seguindo quatro etapas:

I) Conhecimento do corpo. Exercícios em que se começa a conhecer o próprio corpo, sua deformação social e suas possibilidades de recuperação;

2) Expressão pelo corpo. Jogos em que cada pessoa se expressa unicamente pelo corpo, abandonando formas rotineiras de expressão;

3) $\mathrm{O}$ Teatro como Linguagem. Prática do teatro como linguagem viva e presente, com as seguintes gradações:

I- Dramaturgia simultânea - Espectadores "escrevem" simultaneamente aos atores que representam;

2- Teatro-Imagem - Espectadores intervém diretamente, "falando" através das imagens feitas pelos atores;

3- Teatro-Debate - Espectadores intervém diretamente na ação dramática, substituem os atores e atuam.

4) O Teatro como Discurso. O espectador-ator apresenta o espetáculo segundo suas necessidades de discutir certos temas ou de ensaiar certas ações, podem ser:

- Teatro-jornal, teatro-invisível, teatro fotonovela, quebra de repressão, teatro mito, teatro julgamento, rituais e máscaras.

Todas estas gradações da poética do oprimido em Boal visam preparar o espectador para ser um ator, um protagonista na vida em sociedade. São etapas de treinamento em que qualquer pessoa pode assumir seu papel de atividade social na sociedade, utilizando-se do ensaio teatral para esta finalidade. Nestas etapas, o espectador é provocado a abandonar sua condição de objeto e assumir seu papel de sujeito. (p. I5I)

A questão do público como ator está intimamente relacionada às ferramentas de comunicação interpessoal, já que o espectador é convidado a interagir com outras pessoas em cena pela representação, ocupando o papel de ator e de autor de sua 
perspectiva e opinião sobre o tema, numa co-construção ou co-desconstrução comunitária de um contexto apresentado.

O exercício da autenticidade ou espontaneidade acontece quando o receptor de uma mensagem pode tornar-se emissor desta mensagem, invertendo os papéis relacionais da comunicação tradicional e desta forma apropriando-se de seus atos, por esta vivência mais consciente de seu papel ativo nos diversos contextos e situações da sociedade.

Schimidt (2017, p.134-135), relata que "A prática do jogo, seja qual ele for, demanda que o jogador esteja disposto a estabelecer relações, consigo, com os outros jogadores, com os espectadores e com o espaço."

Num relato pessoal, os participantes do Psicodrama Público do CCSP e Diadema compartilham que sair da posição de espectador, plateia e construir um movimento em direção à posição de protagonista possibilita utilização de recursos próprios desconhecidos até o momento, o exercício da empatia e da imaginação pela experiência de papeis que nunca irão de fato ser vivenciados na vida corrente, como presidente da república ou Hittler e outros. A ludicidade da vivência pelo empoderamento de si no "sapato" de outro é de grande valor e aplicabilidade na vida real e concreta dos participantes.

O método de sociodrama é uma proposta de roteiro para um trabalho com o público-alvo, juntando conceitos de Moreno, Brecht e Boal, possibilitando uma ampla e criativa aplicação pedagógica com o público, tendo como tema qualquer assunto das artes ou ciências em qualquer organização, educacional ou não. 


\section{FIM - O CONHECIMENTO PELA DRAMATIZAÇÃO}

Em geral, a epistemologia é o estudo do conhecimento ou das formas de transmitir e adquirir conhecimento. Inclui-se nesta definição o "saber que", o "saber como" e o "saber quem" (familiaridade). O conhecimento pode ser intuitivo ou discursivo. Interessa para este estudo o conhecimento do "saber como" e intuitivo, num primeiro momento. O principal tema na educação da espontaneidade é a ênfase no processo de aprendizagem produtivo, o espontâneo-criativo. Os exercícios e treinamento da espontaneidade são o principal desafio da escola contemporânea.

O questionamento ao público do Psicodrama Público no CCSP e Diadema trata da diferenciação entre dramatização e encenação. A encenação está relacionada à apresentação de uma história, real ou fictícia, por meio de distribuição de papéis em uma determinada situação a um determinado público. Neste, o caminho para chegar ao fim da história é traçado (fixo), ou seja, a escolha do tipo de ação envolvida na história para chegar ao fim é previamente determinada.

A dramatização está mais relacionada ao levantamento dos tipos e alternativas de ação, viáveis ou não, atitudes e comportamentos possíveis para trilhar o caminho ao fim da história desejado. A dramatização dispensa a encenação. A arte dramática está profundamente relacionada às várias técnicas e métodos existentes que justifiquem a escolha de determinada ação e caminho para a encenação de uma história. Num exemplo, a dramatização do ditado popular "Todos os caminhos levam a Roma" consiste em explorar as mais variadas alternativas de percorrer o caminho até Roma, englobando o sentido figurado da citação, podendo haver encenação destas escolhas ou 
não. Somente a discussão pelo método de "brainstorm" (livre expressão de ideias ou ressonâncias) já inicia o processo de dramatização, a arte dramática.

Gopalkrishnan (2015, p.6-8) afirma que a cultura modifica a forma com que lidamos com os extremos tipos de adversidade. E que há variações culturais nos tipos de estressores que as pessoas experimentam assim como diferenças nas escolhas de respostas aos mesmos tipos de estressores.

Trend (2012, p. 616-621) ressalta o trabalho inovador de Giroux no desenvolvimento interdisciplinar entre educação e a arte. Giroux lança a noção de artistas e professores como trabalhadores culturais unidos por um propósito comum. Este termo trabalhador cultural frustra a identificação convencional de cultura com arte, porém entende-o em termos sociológicos e políticos. Este movimento desafia a arte convencional como uma atividade superior à experiência do dia a dia. Giroux estabeleceu uma ampla definição de escrita cultural que engloba a produção, transmissão e organização de subjetividades. Conclama os artistas à professores e os professores à artistas, determinando uma pedagogia crítica e técnica.

Giroux, em sua palestra no YouTube em 2015 (2015, 22'), fala sobre a pedagogia como uma prática de empoderamento, tanto do professor quanto do aluno. Há a necessidade de mobilizar estudantes a se engajarem politicamente e intelectualmente em uma posição crítica aos problemas sociais. Educadores necessitam de uma nova linguagem para não se tornarem desconectados e instrumentalizados, movidos por métodos mecanizados e automatizados, reprodutores de interesses contrários ao desenvolvimento crítico do cidadão. Giroux recebeu um prêmio Paulo Freire pelo desenvolvimento de uma pedagogia crítica. 
Paulo Freire, renomado pedagogo brasileiro conhecido pela pedagogia do oprimido, ressalta a proposta de uma educação crítica que caminha pelo desenvolvimento da autonomia do aluno-cidadão. Impossível comentar brevemente sua grande contribuição a cultura brasileira. Porém, a busca pela autonomia intelectual e emocional é uma constante entre artistas e professores, avessos à cultura da pós-verdade e do fenômeno das fake news.

Em Teixeira (2008, p. 29), "Paulo Freire propõe a superação da relação "opressoroprimido", pela elaboração do conhecimento ligado ao processo de conscientização crítica da realidade...Idealizando uma Educação Libertadora."

O método Paulo Freire consiste em três momentos dialéticos e interdisciplinares:

I) Investigação temática - aluno e professor buscam no universo do aluno e sociedade em que ele vive, as palavras e temas centrais de sua biografia;

2) Tematização - aluno e professor codificam e decodificam estes temas, buscando seu significado social, tomando consciência do mundo vivido;

3) Problematização - aluno e professor buscam superar uma visão mágica (natural) por uma visão crítica, partindo para transformação do contexto vivido." (TEIXEIRA, 2008, p. 48)

"Freire enfatiza o ato pedagógico como uma ação que não consiste em comunicar o mundo, mas criar "dialogicamente" um conhecimento do mundo...Ressalta a importância fundamental de dois elementos na sua filosofia educacional: a conscientização e o diálogo. (TEIXEIRA, 20o8, p. 54)

O sociodrama também pode ser aplicado à pedagogia, como Romaña (1987, p. 4I) descreve um método chamado "psicodrama pedagógico". Que consiste em:

I) Aproximação intuitiva e afetiva - a dramatização é real e surge da experiência ou dados de referência. É o espaço do conhecimento, com um trabalho analítico;

2) Aproximação racional ou conceitual - a dramatização é simbólica, é o tempo do conhecimento, com um trabalho sintético, onde vão surgindo implicações do conhecimento que permitem elaboração do conceito;

3) Aproximação funcional - a dramatização é ao nível da fantasia, é a integração do conhecimento, com um trabalho de aplicação onde criam-se esquemas e associações.

Em Silva (2012, p.2), um dos elementos que determina o processo de aprendizagem e de adquirir conhecimento numa determinada área é a forte associação 
entre o corpo, gesto, e o jogo da imitação. Exercitando a produção de cenas (imitações de contextos ambientais) e a construção de cenários (situações hipotéticas, imitativas da realidade vivida) é possível aprender pela exposição à situação, construindo soluções e saídas para as situações reais da vida em sociedade.

Koudela (I99I, p.98) discorre sobre a questão: "A utilização do teatro como meio educacional, neste caso, busca a investigação e assimilação das vivências pessoais e também históricas, e que se manifesta presente no corpo e na ação dos participantes."

Koudela (I99I, p.98) continua:

A partir da fusão entre ator e espectador, em que o atuante observa suas próprias ações, constrói-se uma perspectiva dialética que realiza uma transformação na função do teatro, no sentido de que adquire um novo princípio na relação ensinar/aprender. Quanto à dialética, essa noção deve ser adquirida na prática, por meio do jogo, como método de ação, mas também ideológico. No caso da peça didática, esta é estabelecida como um modelo para a relação dialética entre teoria e prática"..."a utilização do teatro como meio educacional, neste caso, busca a investigação e assimilação das vivências pessoais e também históricas, e que se manifestam presentes no corpo e na ação dos participantes.

Assim, a arte imita a vida e a arte dramática tem o condão de imitar um movimento de ação em direção ao aprendizado do conhecimento desejado. Nesta técnica de imitar a realidade, a vivência adquirida num contexto irreal, da arte dramática, é a base para o desenvolvimento de conhecimento individual. Este método é proporcionado pelos jogos de simulação, por exemplo, de direção de automóveis ou aeronaves. A arte dramática é uma técnica de proporcionar uma simulação ao públicoalvo visando atingir um objetivo específico. Esta simulação está intimamente ligada ao treinamento de uma ação específica.

Coelho (1989, p. 3I), acrescenta "o processo educacional é um simulacro do processo cultural." O educar aproxima-se do fazer cultura pela simulação, indicando que o primeiro passo de aproximação para estes dois processos é pela arte da imitação. Chega-se a uma ação cultural pela imitação ou simulação do processo educacional. Ainda, esclarece que o teatro pode não ser o caminho mais curto para uma ação cultural, já que como arte específica tem seus próprios objetivos, mas lhe parece o mais completo, por envolver corpo, mente e emoção. (p. 91-92)

Para Coelho (1989, p. 93-94):

$$
\text { [...] a ação cultural visa ativar três esferas do indivíduo e do grupo: }
$$


- a imaginação: onde a consciência se abre para as possibilidades, libertando-se do ser e do dever ser para aceitar o desafio do poder ser;

- a ação: quando o sujeito penetra no tempo presente e viabiliza aquilo que sua imaginação pressentiu, pré-dispôs, ligando-se assim ao processo cultural;

- a reflexão: uma proposta de continuidade de si próprio e de sua ação, numa integração com o passado, permite-lhe um exercício teórico, numa predeterminação do possível. Neste instante, a imaginação é novamente ativada e o círculo se fecha, o processo se conclui.

A construção de conhecimento em conjunto, na sociedade, parte do particular e caminha pela inclusão de todas as pessoas em termos de valor ao conhecimento de linguagens e perspectivas de vida diversas. É o exercício da difusão da autonomia que possibilita o desenvolvimento sustentado de qualquer cultura e sociedade. Em caráter experimental, o método de sociodrama pode ser desenvolvido pelo grupo presencialmente pelo teatro ou à distância pelo cinema, já que as ates cênicas e dramáticas são comuns a estes dois meios de expressão e representação.

\section{CONSIDERAÇÕES FINAIS}

O sociodrama é um método importante a ser considerado em ações transformadoras, educacionais ou culturais. Numa visão mais ampla, a ação cultural visa sempre ativar a imaginação, a ação e a reflexão em qualquer público, os convidando à ação pela dramatização. Não há restrições às aplicações diversas destes princípios do sociodrama na contemporaneidade visando estabelecer uma ação cultural, como: jornalismo cultural, teatro e cinema, desenvolvimento de roteiros diversos, línguas, emoções, expressão corporal, significação de som e cores, lógica, ciências sociais e aplicações, relações interpessoais, relações intrapessoais, autoconhecimento, desenvolvimento de identidade de grupos e organizações, espontaneidade e autonomia ativa, cidadania, cultura e sociedade.

\section{REFERÊNCIAS}

AGUIAR, M. El futuro del teatro espontâneo. Campo Grupal, XIII (130), 2011. Disponível em https://pt.calameo.com/read/oooo49i296289ce274d88. Acessado em I4 dez. 202I. 
AGUIAR, M. (org.). Psicodrama e emancipação - A escola de Tietê. São Paulo: Ágora, 2009. Disponível em http://pepsic.bvsalud.org/pdf/psicodrama/v2In2/ao2.pdf. Acessado em I4 dez. 2021.

BOAL, A. Jogos para atores e não atores. Rio de Janeiro: Civilização Brasileira, I999. Disponível em https://issuu.com/edicoessescsp/docs/trecho_jogos. Acessado em I4 dez. 202I.

. O arco-íris do desejo. Rio de Janeiro: Civilização Brasileira, 1996. Disponível em https://laracoutouvv.files.wordpress.com/2016/o2/boal-augusto-o-arco-c3adris-dodesejo.pdf. Acessado em I4 dez. 2021.

Teatro do Oprimido: e outras poéticas políticas. Editora Cosac Naify, 2014. Disponível em https://artenocampo.files.wordpress.com/2013/o9/teatro-do-oprimidoe-outras-poczagticas-polczadticas-I.pdf. Acessado em I4 dez. 202I.

COElHO, Teixeira. O que é ação cultural. Brasiliense, 1989. Disponível em https://www.academia.edu/ı5999839/O_que_\%C3\%A9_A\%C3\%A_\%C3\%A30_Cultural . Acessado em i4 de dez. 2021.

DESGRANGES, F. A pedagogia do espectador. São Paulo: Hucltec, 2003. Disponível em https://fdocuments.net/document/desgranges-a-pedagogia-do-espectador.html. Acessado em I4 dez. 202I.

GIROUX, H. Where is the outrage? Critical Pedagogy in Dark Times. 2015. in https://www.youtube.com/watch?v=CAxj87RRtsc. Acessado em io dez. 202I.

GOPALKRISHNAN, N.; BABACAN, H. Cultural diversity and mental health. Australasian Psychiatry, v. 23, n. 6_suppl, p. 6-8, 2015. Disponível em https://journals.sagepub.com/doi/ro.1177/1039856215609769?_cf_chl_jschl_tk_=sEKCs 
waiPI6JSF9vaOhFKyhbMMv_3EFLodDhWI26Mm4-I639507964-o-gaNycGzNCDo. Acessado em I4 dez. 202I.

KONDO, J.; KHAN, S. The cultural democracy myth. Contexts, v. io, n. I, p. 65-66, 20II. Disponível em https://doi.org/Io.I177/I5365042II399055. Acessado em I4 dez.202I.

KOUDELA, I. D. Brecht: um jogo de aprendizagem. São Paulo: Edusp/Perspectiva, 1991. Disponível em https://editoraperspectiva.com.br/produtos/brecht-um-jogo-deaprendizagem/. Acessado em I4 dez.2021.

LIMA, M. A.. Eu sou índio. In: O NACIONAL e o popular na cultura brasileira: seminários - teatro. São Paulo: Brasiliense, 1983. p. I63-171. Disponível em http://cremeja.org/a7/acervo-digital/fundo-osmar-favaro/educacao-popular-i/cpc/onacional-e-o-popular-na-cultura-brasileira-marilena-chaui-seminario-iii/. Acessado em 14 dez. 202I.

MORENO, J. L. O teatro da Espontaneidade. ed. Agora, 2012. Disponível em https://www.travessa.com.br/o-teatro-da-espontaneidade-I-ed-2012/artigo/d9169c55b7eo-4e7c-bfaf-dd9763ecc5oa. Acessado em i4 dez. 2021.

Os cinco componentes do psicodrama. 1948, video disponível em https://www.youtube.com/watch?v=XDno7uZrtmc. Acessado em I4 dez. 2021.

Psicodrama. Editora Cultrix, 1993. Disponível em https://www.estantevirtual.com.br/livros/j-1-moreno/psicodrama/4123984230. Acessado em I4 dez. 2021.

NIZO, R. O meu, o seu, o nosso querer: ferramentas para a comunicação interpessoal. Ed. Ágora. 2007. Disponível em https://www.travessa.com.br/o-meu-o-seu-o-nossoquerer-ferramentas-para-a-comunicacao-social-ı-ed-2007/artigo/f 477767 of-gf 72 -48a3bdar-babe25di8a54. Acessado em I4 dez. 2021. 
ROMAÑA, M. A. Psicodrama pedagógica: método educacional psicodramático. Papirus, 1987.

SILVA, A. C. T. F.; DAL GALLO, F.. Gestus social na costa do dendê: ressignificação da peça didática de Bertolt Brecht para o ensino teatral em comunidade. Anais SCHIMIDT, M. Presença cênica e jogo: articulações e tensões nas construções poéticas como ator. Bahia, 2017. Disponível em https://repositorio.uft.edu.br/handle/11612/513. Acessado I4 dez. 2021.

TEIXEIRA, T. M. B. Dimensões socioeducativas do Teatro do Oprimido Paulo Freire e Augusto Boal. Universitat Autõnoma de Barcelona, 2008. Disponível em https://www.tesisenred.net/bitstream/handle/10803/4657/tmbtrder.pdf?sequence $=\mathrm{I} \&$ is Allowed=y. Acessado em i4 dez. 2021.

TREND, D. Henry Giroux and the Arts. Policy Futures in Education, v. Io, n. 6, p. 61662I, 2012.

https://journals.sagepub.com/doi/pdf/ı.2304/pfie.2012.10.6.616. Acessado em 14 dez. 2021. 